\title{
Patency rates of endoscopically harvested radial arteries one year after coronary artery bypass grafting
}

Sabine Bleiziffer, MD, ${ }^{a}$ Ina Hettich, MD, ${ }^{a}$ Birgit Eisenhauer, ${ }^{a}$ Daniel Ruzicka, MD, ${ }^{a}$ Michael Wottke, MD, ${ }^{a}$ Joerg Hausleiter, MD, ${ }^{\text {b }}$ Stefan Martinoff, $\mathrm{MD}^{\mathrm{c}}$ Martin Morgenstern, MD, ${ }^{\mathrm{d}}$ and Ruediger Lange, $\mathrm{PhD}, \mathrm{MD}^{\mathrm{a}}$

Objectives: To improve patients' acceptance of the radial artery as a graft for coronary revascularization, we introduced an endoscopic harvesting technique. The aim of this study was to assess graft quality 1 year after the operation.

Methods: In 50 patients who underwent endoscopic radial artery harvesting for coronary artery bypass grafting, 64-slice computed tomography, electrocardiography, and echocardiography were utilized to assess graft patency and left ventricle function at a 1-year follow-up. In addition, the influencing factors of radial artery graft patency were evaluated. Radial artery patency was compared with a control group from our database.

Results: Any patency of endoscopically harvested radial artery grafts was 78\% (39/50) and perfect patency was 72\% (36/50) 1 year after coronary revascularization. The implanting surgeon and graft harvester, patient factors, graft properties, medication, and target territory did not influence the patency rates of the radial artery graft. The only significant and strong parameter to predict perfect graft patency was the severity of the target vessel stenosis $(P<.001)$. In patients with a target vessel stenosis of $90 \%$ or greater, radial artery graft patency was $90.3 \%$ (28/31). Patency rates of endoscopically (72\%) and conventionally (74\%) harvested radial arteries were not different $(P=.822)$.

Conclusions: Patency rates 1 year after endoscopic radial artery harvesting are comparable to the open technique. On the basis of our results, we attempt to use the radial artery as a bypass graft only for target coronary arteries with $90 \%$ or greater stenosis. We recommend endoscopic harvesting as the technique of choice to harvest the radial artery.

From the Clinic for Cardiovascular Surgery, ${ }^{a}$ Clinic for Cardiology, ${ }^{\mathrm{b}}$ and Institute for Radiology, ${ }^{\mathrm{c}}$ German Heart Center Munich; and Department for Internal Medicine I, Clinical Center Rosenheim, ${ }^{\mathrm{d}}$ Munich, Germany.

Received for publication Sept 21, 2006; revisions received April 2, 2007; accepted for publication April 11, 2007.

Address for reprints: Sabine Bleiziffer, MD, Clinic for Cardiovascular Surgery, German Heart Center Munich, Lazarettstr. 36, 80636 Munich, Germany (E-mail: bleiziffer@dhm.mhn.de).

J Thorac Cardiovasc Surg 2007;134:649-56 $0022-5223 / \$ 32.00$

Copyright (c) 2007 by The American Association for Thoracic Surgery

doi:10.1016/j.jtcvs.2007.04.008
$\mathrm{S}$ ince the reintroduction of the radial artery (RA) as a coronary artery bypass graft in the 1990s, harvesting techniques and antispasmodic therapy have been advanced. ${ }^{1-3}$ It has been hoped that the RA will maintain greater late patency than has the saphenous vein (SV). ${ }^{4}$ Consequently, we offer total arterial revascularization to patients aged less than 70 years. To further improve patients' acceptance of the RA as a bypass graft, we established a method of endoscopic RA harvesting in March of 2004. ${ }^{5}$

To evaluate the graft patency of the endoscopic technique, we consecutively followed up our first series of patients who underwent endoscopic RA harvesting.

\section{Materials and Methods \\ Patients}

Of 1403 patients who underwent coronary artery bypass grafting at our institution between March 2004 and July 2005, 397 received an RA graft. The RA was chosen as a bypass graft in patients aged less than 70 years and in the absence of contraindications such as carpal tunnel syndrome, Dupuytren disease, severe arterial obstructive disease, dialysis, pathologic Allen test or Doppler examination, small RA diameter, or visible calcification. A total of 71 


\author{
Abbreviations and Acronyms \\ LITA $=$ left internal thoracic artery \\ MSCT $=$ multislice computed tomography \\ NYHA $=$ New York Heart Association \\ PI = pulsatility index \\ RA $=$ radial artery \\ RCA = right coronary artery \\ RITA = right internal thoracic artery \\ $\mathrm{SV}=$ saphenous vein
}

patients underwent coronary artery bypass grafting with an endoscopically harvested RA during the above-mentioned time period. Twelve patients were lost to follow-up (10 patients live abroad and 2 patients refused follow-up). Of 59 patients, 6 refused the investigation with a multislice computed tomograph (MSCT), and 3 patients had contraindications for the application of the contrast agent (elevated creatinine or suppressed thyroid-stimulating hormone). Thus, evaluation of bypass patency after endoscopic RA harvesting at 1 year was performed in 50 patients. In these patients, a 12-lead electrocardiogram was recorded and an echocardiographic investigation was performed.

\section{Endoscopic Radial Artery Harvesting}

The nondominant arm was chosen for RA harvesting. Preoperative Allen test and Doppler examination were routinely performed to confirm adequate ulnar blood flow.

The RA was harvested through a single 3-cm skin incision. This technique is performed with an endoscope inserted into a retractor and a harmonic scalpel for the dissection of the artery. Transection of the artery is carried out with a pre-tied Endoloop. A detailed description of the technique has been published. ${ }^{5}$

Antispasmodic prophylaxis was carried out by intravenous application of 6 to $12 \mu \mathrm{g}$ diltiazem $/ \mathrm{kg} / \mathrm{min}$ starting during extracorporeal circulation and continuing for 24 hours after the operation. We also recommended the administration of amlodipine as an antispasmodic agent in an oral dose of $5 \mathrm{mg} / \mathrm{d}$ for 3 months after the operation.

\section{Intraoperative Assessment}

Assessment of the bypass grafts was carried out after weaning from cardiopulmonary bypass and establishment of stable hemodynamic conditions with a transit time flowmeter (Medi-Stim ASA, Oslo, Norway). Mean graft flow and pulsatility index (PI) were obtained directly from the flowmeter.

\section{Assessment of the Target Vessel Stenosis}

Data concerning the severity of the target vessel stenosis for bypass grafting were collected from the preoperative angiograph, from which native coronary artery stenosis was determined by visual assessment.

\section{Multislice Computed Tomographic Angiographic Analysis}

A computed tomographic angiographic scan is routinely performed 1 year after coronary artery bypass grafting. Contrast-enhanced com- puted tomographic angiographic data (Sensation 64 Cardiac, Siemens Medical Solutions, New York, NY) were acquired with the use of a spiral scan with $32 \times 0.6-\mathrm{mm}$ collimation, $330 \mathrm{~ms}$ gantry rotation, pitch of 0.2 , and tube voltage at $120 \mathrm{kV}$. The scanning range included the entire course of venous grafts and the most proximal part of internal thoracic artery grafts at their subclavian origin, if these arterial grafts had been used for bypass surgery.

All bypass grafts were independently evaluated by 2 investigators who were aware of the initial coronary artery bypass grafting procedure. The investigators independently evaluated the contrast-enhanced MSCT scans by assessment of the axial slices, multiplanar reformations, and 3 thin-slab maximum intensity projections. Lumen narrowings were classified by the maximal luminal diameter stenosis seen in any plane. Because localized bypass stenoses were not seen in the present cohort, the bypass grafts were classified as perfectly patent, patent, or occluded. All patients signed an informed consent.

\section{Echocardiographic Analysis}

All echocardiographic examinations were performed by an experienced investigator. Echocardiographic scanning was carried out under resting conditions using an image Point $\mathrm{Hx}$ ultrasound system with a $2.5-\mathrm{MHz}$ transducer (Hewlett-Packard, Palo Alto, Calif). Measurements of left ventricular dimensions were performed in the long parasternal axis. Left ventricular function and wall motion abnormalities were evaluated by visual assessment. ${ }^{6}$

\section{Control Group}

To compare RA graft patency rate after endoscopic harvest (ENDO group) with the conventional open technique (OPEN group), 50 patients who had undergone coronary artery bypass grafting with a conventionally harvested RA in the abovementioned time period were randomly and retrospectively selected from our database and served as controls. The patient characteristics and type of grafts implanted in the ENDO and OPEN groups are summarized in Tables 1 and 2. Assessment of the target vessel stenosis and antispasmodic prophylaxis were performed in the control group as described above. Assessment of bypass graft patency was performed by MSCT in 33 patients of the control group and by angiography in 17 patients who had been followed up in an external clinic.

\section{Statistics}

Data are presented as mean \pm standard deviation or as percentages. Differences between groups were tested with the Student $t$ test for continuous variables and the chi-square test or Fisher exact test for dichotomous variables as appropriate. Eighteen variables (patient characteristics, graft and target vessel properties) were tested for their influence on RA patency.

We performed a logistic regression analysis for patency of the RA after endoscopic harvest. We used forward selection and the likelihood ratio test for model selection. Included were age, gender, and all variables with a $P$ value less than .10 in the univariate tests. Because normal distribution and homogeneity of variances were not given, a $P$ value of less than .01 was considered statistically significant. Data analysis was performed with the Statistical Package for the Social Sciences version 14.0.1 (SPSS Inc, Chicago, Ill). 
TABLE 1. Patient baseline characteristics

\begin{tabular}{|c|c|c|c|}
\hline & $\begin{array}{c}\text { ENDO } \\
(n=50)\end{array}$ & $\begin{array}{c}\text { OPEN } \\
(n=50)\end{array}$ & $\boldsymbol{P}$ \\
\hline Gender (female/male) & $6 / 44$ & $8 / 42$ & .564 \\
\hline Age $(y)$ at time of operation & $60.1 \pm 6.7$ & $59.2 \pm 8.2$ & .548 \\
\hline Concomitant procedures & & & .695 \\
\hline Aortic valve replacement & $\mathrm{n}=2$ & $\mathrm{n}=2$ & \\
\hline $\begin{array}{l}\text { Aorta ascendens } \\
\text { replacement }\end{array}$ & $\mathrm{n}=1$ & & \\
\hline Mitral valve replacement & & $\mathrm{n}=1$ & \\
\hline Tricuspid repair & & $\mathrm{n}=1$ & \\
\hline Incidence of smoking history & $15 / 50$ & $19 / 50$ & .398 \\
\hline $\begin{array}{l}\text { Incidence of diabetes } \\
\text { mellitus }\end{array}$ & $6 / 50$ & $10 / 50$ & .275 \\
\hline $\begin{array}{l}\text { Incidence of hyperlipidemia } \\
\text { treated with statins }\end{array}$ & $24 / 50$ & $34 / 50$ & .043 \\
\hline $\begin{array}{l}\text { Incidence of peripheral } \\
\text { vessel disease }\end{array}$ & $4 / 50$ & $6 / 50$ & .505 \\
\hline $\begin{array}{l}\text { Incidence of hypertension } \\
\text { untreated }\end{array}$ & $3 / 50$ & 0 & .137 \\
\hline treated & $37 / 50$ & $43 / 50$ & \\
\hline $\begin{array}{l}\text { Preoperative ejection } \\
\text { fraction }\end{array}$ & $56.5 \% \pm 7.8 \%$ & $54.0 \% \pm 10.8 \%$ & .189 \\
\hline
\end{tabular}

ENDO, Endoscopically harvested radial artery; OPEN, conventional open radial artery harvest.

\section{Results}

\section{Clinical Outcome}

All patients are alive at $11.1 \pm 1.5$ months after the initial operation. In the ENDO group, 33 of 50 patients $(66 \%)$ are in New York Heart Association (NYHA) class I, 16 of 50 patients $(32 \%)$ are in NYHA class II, and 1 patient $(2 \%)$ is in NYHA class III. The mean ejection fraction was $56.5 \% \pm$ $8 \%$ preoperatively and is $57.4 \% \pm 6 \%$ at follow-up $(P=$ .294).

In both groups, no cardiac reoperations have been performed. One patient has hemiparesis caused by postopera- tive apoplexy (ENDO group), and 1 patient underwent lateral thoracotomy for postoperative hematothorax (ENDO group). In 5 patients, sternal revision was performed (ENDO: $n=1$, OPEN: $n=4$ ). In 1 patient of the OPEN group, postoperative rethoracotomy was performed because of bleeding. No reinterventions have been necessary on the RA harvesting site in the ENDO group, whereas 1 patient in the OPEN group underwent wound revision. The surgical and catheter interventions performed in this series are summarized in Table 3.

\section{Graft Patency}

In the ENDO group, any patency rate of the RA grafts was $78 \%(39 / 50)$, and perfect patency rate was $72 \%(36 / 50)$. Patency rate was $98 \%$ (47/48) for the left internal thoracic artery (LITA) grafts, $86 \%$ (12/14) for the right internal thoracic artery (RITA) grafts, and 69\% (11/16) for the SV grafts after a follow-up of $11.1 \pm 1.5$ months. Of 14 occluded RA grafts, 11 were completely occluded and 3 showed severe string signs and thus were functionally occluded. Those grafts may maintain any residual minimal flow. In 1 of the 3 patients with functionally occluded RA grafts, angiography was performed, and the computed tomography findings were confirmed. Figure 1 shows an example with 1 occluded and 2 patent bypass grafts.

Compared with the OPEN group, there was no difference in any patency of the RA grafts (ENDO: 78\% [39/50] vs OPEN: $76 \%$ [38/50], $P=.812$ ) and in perfect patency (ENDO: 72\% [36/50] vs OPEN 74\% [37/50], $P=.822$ ) after endoscopic RA harvest. There were also no significant differences between the groups in LITA, RITA, and SV graft patency rates.

\section{Echocardiographic and Electrocardiographic Results (ENDO Group)}

A total of 47 of 50 patients are in sinus rhythm, and 2 patients have an implanted pacemaker. One patient has

TABLE 2. Distribution of graft types

\begin{tabular}{|c|c|c|c|c|c|c|c|c|}
\hline \multirow[b]{3}{*}{ Target vessel } & \multicolumn{8}{|c|}{ Type of bypass graft } \\
\hline & \multicolumn{2}{|c|}{$\mathbf{R A}^{*}$} & \multicolumn{2}{|c|}{ LITA* } & \multicolumn{2}{|c|}{ RITA* } & \multicolumn{2}{|c|}{ SVG* } \\
\hline & $\begin{array}{c}\text { ENDO } \\
\mathrm{n}=\mathbf{5 0}\end{array}$ & $\begin{array}{c}\text { OPEN } \\
\mathrm{n}=\mathbf{5 0}\end{array}$ & $\begin{array}{c}\text { ENDO } \\
\mathrm{n}=48\end{array}$ & $\begin{array}{c}\text { OPEN } \\
\mathrm{n}=48\end{array}$ & $\begin{array}{c}\text { ENDO } \\
\mathrm{n}=14\end{array}$ & $\begin{array}{c}\text { OPEN } \\
\mathrm{n}=\mathbf{2 2}\end{array}$ & $\begin{array}{c}\text { ENDO } \\
\mathrm{n}=16\end{array}$ & $\begin{array}{l}\text { OPEN } \\
\mathrm{n}=\mathbf{8}\end{array}$ \\
\hline LAD & 0 & $1 / 50(2 \%)$ & $48 / 48(100 \%)$ & $48 / 48(100 \%)$ & 0 & 0 & 0 & 0 \\
\hline Diag & $4 / 50(8 \%)$ & $9 / 50(18 \%)$ & 0 & 0 & 0 & 0 & $5 / 16(31 \%)$ & $1 / 8(13 \%)$ \\
\hline Marg & $34 / 50(68 \%)$ & $34 / 50(68 \%)$ & 0 & 0 & $2 / 14(14 \%)$ & $1 / 22(5 \%)$ & $1 / 16(6 \%)$ & $2 / 8(25 \%)$ \\
\hline$c x$ & $2 / 50(4 \%)$ & $1 / 50(2 \%)$ & 0 & 0 & 0 & 0 & 0 & 0 \\
\hline RCA & $10 / 50(20 \%)$ & $5 / 50(10 \%)$ & 0 & 0 & $12 / 14(86 \%)$ & $21 / 22(95 \%)$ & $10 / 16(63 \%)$ & $5 / 8(63 \%)$ \\
\hline
\end{tabular}

ENDO, Endoscopically harvested radial artery; OPEN, conventional radial artery harvest; $C X$, circumflex artery; Diag, diagonal branch; $L A D$, left anterior descending artery; LITA, left internal thoracic artery; Marg, marginal branch; RA, radial artery; RCA, right coronary artery; RITA, right internal thoracic artery; $S V G$, saphenous vein graft. *There were no significant differences in the distribution of grafts to target territories between the ENDO and OPEN groups. 
TABLE 3. Complications requiring surgical or catheter interventions

\begin{tabular}{lcc}
\hline Intervention & ENDO & OPEN \\
\hline Angiography and stent implantation for & & \\
RA graft occlusion & 1 & 3 \\
LITA graft occlusion & 1 & 0 \\
RITA graft occlusion & 0 & 2 \\
SV graft occlusion & 1 & 1 \\
Combined RITA and RA graft occlusion & 1 & 0 \\
Combined LITA and RA graft occlusion & 0 & 1 \\
Lateral thoracotomy after postoperative & 1 & 0 \\
$\quad$ hematothorax & & \\
Sternal revision & 1 & 4 \\
Rethoracotomy because of bleeding & 0 & 1 \\
RA harvesting arm wound revision & 0 & 1 \\
\hline
\end{tabular}

ENDO, Endoscopically harvested radial artery; OPEN, conventional radial artery harvest; $R A$, radial artery; $S V$, saphenous vein; $L I T A$, left internal thoracic artery; RITA, right internal thoracic artery.

multiple premature ventricular complexes, but his bypass grafts are patent. In 39 patients, left ventricular function is normal. Wall motion abnormalities are evident in 11 patients $(\mathrm{n}=2$ anterior wall hypokinesia, $\mathrm{n}=1$ posterior wall hypokinesia, $\mathrm{n}=1$ lateral wall hypokinesia, $\mathrm{n}=6$ septal dyskinesia and $n=1$ diastolic dysfunction). Among the patients with wall motion abnormalities, 2 had an occluded RA graft.

\section{Factors Influencing Radial Artery Graft Patency (ENDO Group)}

To reveal factors affecting perfect RA graft patency after endoscopic RA harvesting, we tested the influence of patient characteristics, graft properties, postoperative medication, and target vessel properties (Table 4). Logistic regression revealed the severity of the target vessel stenosis as the only parameter indicating a significant and strong correlation with the patency rate $(P<.001)$ (Table 5$)$. In the group of patients with a target vessel stenosis of $90 \%$ or greater, 28 of 31 grafts $(90.3 \%)$ were patent. The patency rate was 2.1 times higher in patients with a target vessel stenosis of $90 \%$ or greater. Mean target vessel stenosis had been $88.6 \% \pm$ $16 \%$ in all patients with a perfectly patent RA graft versus $72.9 \% \pm 15 \%$ in patients with an occluded graft $(P=.003)$. Grafts with a flow rate of less than $55 \mathrm{~mL} / \mathrm{min}$ seem to be more prone for occlusion (a flow of $<55 \mathrm{~mL} / \mathrm{min}$ occurred in $13 / 36$ patent grafts vs $11 / 14$ occluded grafts, $P=.007$ ). However, graft flow was not detected as a significant factor influencing RA graft patency in the analysis of variances. Apparently, the learning curve of the first cases had no influence on patency; among our first 20 cases, only 1 RA graft was occluded.

In accordance with these findings, in our control group (conventional RA harvest), patients with a target vessel

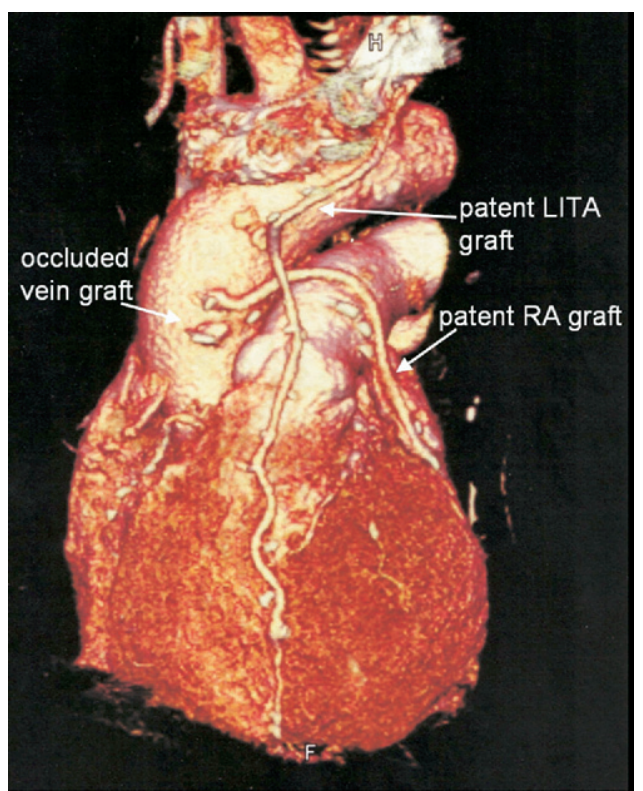

Figure 1. Computed tomographic scan of a 3-dimensional reconstruction with a LITA graft to the left anterior descending artery (patent), an RA graft to the marginal branch (patent), and an SV graft to the RCA (occluded). LITA, Left internal thoracic artery; $R A$, radial artery.

stenosis of $90 \%$ or greater exhibited an RA patency rate of $92 \%(22 / 24)$ versus $58 \%(15 / 26)$ in patients with a target vessel stenosis less than $90 \%(P=.006)$.

\section{Consequences in Patients with Occluded Radial Artery Graft (ENDO Group)}

Among 14 of 50 patients with an occluded RA graft, 11 had no clinical symptoms. We recommended an exercise electrocardiogram to those patients to identify potential ischemia. Only 4 patients followed the recommendation, and all showed no signs of ischemia during exercise. Three patients with an occluded RA graft had angina during exercise. These patients had a target vessel stenosis of $80 \%$ to $100 \%$. One of these patients had undergone stent implantation into the right coronary artery (RCA) because his RITA bypass was also occluded, resulting in an improvement of his symptoms. One patient refused angiography, and 1 patient with an occluded RA-RCA graft underwent stent implantation into the RCA.

\section{Discussion}

In addition to the favorable features of the RA as a bypass graft, such as optimal length, easy handling because of the thick muscular wall, and availability even in patients with varicosis, the endoscopic harvesting technique offers additional benefits. A scar of only $3 \mathrm{~cm}$ at the wrist provides excellent cosmetic results, leading to higher acceptance by 
TABLE 4. Factors influencing radial artery graft patency (ENDO group)

\begin{tabular}{|c|c|c|c|c|}
\hline \multirow{2}{*}{$\begin{array}{l}\text { Variable } \\
\text { Target vessel properties }\end{array}$} & \multicolumn{3}{|l|}{ Results } & $P$ value \\
\hline & & & & \\
\hline \multirow[t]{3}{*}{ Target vessel stenosis $\geq 90 \%$} & Target vessel stenosis & (P) & (0) & \multirow[t]{3}{*}{$<.001$} \\
\hline & $<90 \%$ & 8 & 11 & \\
\hline & $\geq 90 \%$ & 28 & 3 & \\
\hline Target vessel stenosis as a continuous variable & Target vessel stenosis $88.6 \% \pm 16 \%$ (P & $.9 \%=$ & $(0)$ & .003 \\
\hline \multirow[t]{5}{*}{ Target territory } & Target vessel & $(P)$ & $(0)$ & \multirow[t]{5}{*}{.445} \\
\hline & Marg & 23 & 11 & \\
\hline & $\mathrm{CX}$ & 1 & 1 & \\
\hline & RCA & 8 & 2 & \\
\hline & Diag & 4 & 0 & \\
\hline \multirow{6}{*}{$\begin{array}{l}\text { Target vessel stenosis at follow-up (CTA data) } \\
\text { (28\% data missing because of difficulty in } \\
\text { stenosis assessment in calcified coronaries) }\end{array}$} & & $(\mathrm{P})$ & (0) & \multirow[t]{6}{*}{.334} \\
\hline & $0 \%-25 \%$ & 5 & 3 & \\
\hline & $25 \%-50 \%$ & 4 & 3 & \\
\hline & $50 \%-75 \%$ & 5 & 4 & \\
\hline & $75 \%-99 \%$ & 6 & 1 & \\
\hline & $100 \%$ & 5 & 0 & \\
\hline \multicolumn{5}{|l|}{ Graft properties } \\
\hline Graft flow & \multicolumn{3}{|c|}{ Mean graft flow $(\mathrm{mL} / \mathrm{min}): 69.6 \pm 32(\mathrm{P})$ vs $51.6 \pm 33(0)$} & .084 \\
\hline PI value & \multicolumn{3}{|c|}{ PI value: $2.2 \pm 0.9(\mathrm{P})$ vs $2.9 \pm 2.0(0)$} & .240 \\
\hline Visible spasm & \multicolumn{3}{|l|}{ Visible spasm: $1 / 35(\mathrm{P})$ vs $0 / 14(0)$} & .529 \\
\hline \multicolumn{5}{|l|}{ Patient characteristics } \\
\hline Hyperlipidemia treated with statins & \multicolumn{3}{|c|}{ Incidence of hyperlipidemia: 20/36 (P) vs 4/14 (0) } & .086 \\
\hline Preoperative ejection fraction & \multicolumn{3}{|c|}{ Mean ejection fraction (\%): $55.5 \pm 8.9(\mathrm{P})$ vs $59.2 \pm 2.4(0)$} & .131 \\
\hline Smoking history & \multicolumn{3}{|c|}{ Incidence of smoking history: $12 / 36(P)$ vs $3 / 14(0)$} & .409 \\
\hline Diabetes mellitus & \multicolumn{3}{|c|}{ Incidence of diabetes mellitus: $5 / 34(P)$ vs $1 / 14(0)$} & .510 \\
\hline Peripheral vascular disease & \multicolumn{3}{|c|}{$\begin{array}{l}\text { Incidence of peripheral vascular disease: } 3 / 36(P) \\
\text { vs } 1 / 14(0)\end{array}$} & .889 \\
\hline Age & \multicolumn{3}{|c|}{ Mean age $(y): 60.4 \pm 6(P)$ vs $59.3 \pm 9(0)$} & .577 \\
\hline Female gender & \multicolumn{3}{|l|}{ Female gender: $4 / 36(P)$ vs $2 / 14(0)$} & .756 \\
\hline \multicolumn{5}{|l|}{ Medication } \\
\hline \multirow[t]{4}{*}{ Application of amlodipine } & Duration of amlodipine application: & $(\mathrm{P})$ & (0) & \multirow[t]{4}{*}{.248} \\
\hline & No & 3 & 1 & \\
\hline & $3 \mathrm{mo}$ & 16 & 10 & \\
\hline & $1 \mathrm{y}$ & 16 & 3 & \\
\hline \multirow[t]{4}{*}{ Application of norepinephrine } & Amount of norepinephrine application: & $(\mathrm{P})$ & (0) & \multirow[t]{4}{*}{.641} \\
\hline & No & 18 & 9 & \\
\hline & $<5 \mathrm{mg}$ & 9 & 2 & \\
\hline & $>5 \mathrm{mg}$ & 8 & 3 & \\
\hline Personnel factors & & & & \\
\hline Graft harvester $(\mathrm{n}=4)$ & & & & .630 \\
\hline Surgeon $(n=9)$ & & & & .885 \\
\hline
\end{tabular}

$P$, Patent grafts; 0 , occluded grafts; $P I$, pulsatility index; Marg, marginal branch; $C X$, circumflex artery; $R C A$, right coronary artery; Diag, diagonal branch; CTA, computed tomography angiography.

the patient than a scar of 25 to $30 \mathrm{~cm}$ across the forearm, which is permanently visible in everyday life. Minor complications, such as hematomas or wound infections, are also reported to be reduced with the endoscopic technique. ${ }^{7}$ However, there is no consensus about RA patency at midterm and long-term follow-up, although most studies report encouraging RA patency. Therefore, we sought to assess the patency of the RA bypass grafts in our first series of patients after endoscopic graft harvesting.
Patency rates published in the literature range from $51.3 \%(204 / 398)$ after $1.6 \pm 1.4$ years $^{8}$ to $99.0 \%(100 / 101)$ after $2.9 \pm 2.3$ years. $^{9}$ Most studies lack a prospective randomized design and must be interpreted with caution. ${ }^{10}$ A prospective randomized study showed no superiority of the RA over the SV graft when anastomosed randomly to the largest available coronary artery. ${ }^{11}$ In contrast, the prospective randomized Radial Artery Patency Study trial showed a significantly lower occlusion rate for the RA 
TABLE 5. Results of the logistic regression analysis (ENDO group)

\begin{tabular}{lcccrrr}
\hline & Regression coefficient & Standard error & Wald & df & $\boldsymbol{P}$ value & Exp(B) \\
\hline Target vessel stenosis & 2.516 & 0.766 & 10.795 & 1 & 12.375 \\
Constriction & -2.197 & 0.609 & 13.035 & 1 & 0.111 \\
\hline
\end{tabular}

$d f$, Degrees of freedom.

versus the SV graft at 1-year angiography. ${ }^{4}$ A recent prospective randomized trial also showed superior patency of the RA (95\%) over SV (79\%) grafts at a 5-year follow up in 101 patients. In this study, all grafts were anastomosed to the circumflex territory with a target vessel stenosis greater than $75 \% .^{12}$ A recent review article from Manabe and Sunamori ${ }^{13}$ describes a graft patency of $78.5 \%$ when the RA was anastomosed to the left circumflex territory and of $74.1 \%$ when anastomosed to the RCA territory. These data are comparable to our results with perfect patency rates of $67 \%$ (left circumflex territory) and 80\% (RCA territory) with an overall rate of any patency of $78 \%$ and a perfect patency rate of $72 \%$. Concerning mortality after coronary artery bypass grafting, Zacharias and associates ${ }^{14}$ found a significantly better cumulative 0- to 6-year survival in patients with RA versus SV grafts.

To our knowledge, we are the first to describe a prospective investigation of the patency rate 1 year after endoscopic RA harvest in a cohort of 50 patients. Some studies report early results. Miles and colleagues ${ }^{15}$ describe no readmission for postoperative angina that would have required recatheterization in their first 50 patients after endoscopic RA harvesting at a 30-day follow-up. Yoshizaki and colleagues ${ }^{16}$ describe patent RA grafts in 5 patients who underwent endoscopic RA harvesting and postoperative angiography. In the series of Massetti and colleagues, ${ }^{17} 15$ of 15 RA grafts were patent postoperatively, also assessed by angiography. The perfect patency rate of $72 \% 1$ year after endoscopic RA harvesting in our series seems comparable to patency rates after conventional RA harvest published in the literature; however, no randomized data are available. To explore whether the RA patency is influenced by the endoscopic technique, we compared our data with a retrospective control group of patients who underwent conventional open RA harvest during the same time period. We could not demonstrate a difference between perfect RA patency after endoscopic (72\%) versus open RA harvest $(74 \%, P=.822)$, whereas the 2 groups did not differ in baseline characteristics and target territories. Presumably, the use of the harmonic scalpel versus electrocautery may influence the patency more than the endoscopic or conventional technique. Endoscopic and conventional harvesting systems are available with the harmonic scalpel or with electrocautery. A study from Onorati and colleagues ${ }^{18}$ indicates better flowmetry and PI of the RA harvested with the harmonic scalpel versus electrocautery, whereas Cikirikcio- glu and colleagues ${ }^{19}$ and Shapira and colleagues ${ }^{20}$ found no alterations in vasoreactivity or endothelial integrity for either technique.

Nevertheless, we had expected superior RA patency rates and thus aimed to identify factors influencing patency after endoscopic RA harvesting. Personnel factors such as the graft harvester or the graft implanting surgeon, as well as the learning curve, did not influence the RA patency. Furthermore, patient gender and age also did not influence the patency. Visible spasm of the RA after the harvest occurred in 1 case, and this graft was patent after 1 year. Intraoperatively assessed graft flow and PI tended to be better in RA grafts that were patent after 1 year, but this difference was not significant. It was not possible to evaluate a PI threshold value to predict graft occlusion. With regard to flow rate, grafts with a flow of less than $55 \mathrm{~mL} / \mathrm{min}$ seemed to be more prone for occlusion $(P=.007)$. Calcium-channel antagonists show proven antispasmodic effect on the RA, ${ }^{21}$ with dihydropyridine derivatives such as nifedipine or amlodipine being the most potent calcium antagonists. Therefore, we recommend the oral administration of amlodipine for at least 3 months after the operation. The length of amlodipine application ( 3 months or 1 year) did not correlate with RA patency in our series. Although the RA is more prone to vasoconstriction in the presence of norepinephrine ${ }^{22}$ the postoperative amount of norepinephrine application did not affect RA patency as well. In our series, we could not demonstrate an impact of diabetes mellitus, smoking history, peripheral vessel disease, or hyperlipidemia on 1-year RA patency. This might be, at least in part, attributable to the low incidence of these risk factors in our patient population (Table 1). Also, the coronary territory to which the RA was anastomosed had no influence, which has also been described by Tatoulis and colleagues. ${ }^{23}$ In our cohort, the only significant and strong predictor of 1-year RA perfect patency was the severity of target vessel stenosis (Table 5). In the group of patients with a target vessel stenosis of $90 \%$ or greater, RA graft perfect patency was as high as $90.3 \%(28 / 31)$. With a target vessel stenosis of less than $90 \%$, perfect patency was only $42 \%$ (8/19), indicating that RA grafts are prone to occlusion in the presence of competitive coronary flow. In our retrospective control group, this relation was also present, because perfect patency was 92\% (22/24) in RA grafts anastomosed to target vessels 
with a stenosis of $90 \%$ or greater versus $58 \%(15 / 26)$ when target vessel stenosis was less than 90\% $(P=$ .006). In our series, this effect was distinct. Desai and colleagues $^{24}$ speculate "that progressive auto-regulated adaptive narrowing of the RA conduit in the setting of competitive flow" may be the mechanism of graft occlusion. Royse and colleagues ${ }^{25}$ defined $70 \%$ coronary stenosis as a "cut-off" point. Below this degree of stenosis, the long-term patency of the RA was found to be significantly decreased. In accordance with our findings, Desai and associates ${ }^{4}$ described a significantly lower RA patency even when target vessel stenosis is less than $90 \%$ and recommend RA grafting to severely stenotic targets $(>90 \%)$ to improve patency in a recent article. ${ }^{24}$ Fortunately, most of our patients with an occluded RA graft have no clinical symptoms, indicating that the rate of silent occlusion is high. Freedom from angina or dyspnea does not implicate RA graft patency.

In our cohort, the patency rates of LITA grafts $(98 \%$, 47/48) and RITA grafts (86\%, 12/14) were satisfactory, whereas SV graft patency was less than expected (69\%, 11/16). This may be because the SV was chosen as the graft of third choice after the LITA and a second arterial graft in this patient population.

\section{Conclusions}

Patency rates 1 year after endoscopic RA harvesting are comparable to those of a control group with conventional harvest and to reports in the literature. In view of the advantages of the endoscopic technique, we recommend this approach as the technique of choice to harvest the RA. The target coronary artery for RA grafts must be selected with caution. On the basis of our results, we attempt to use the RA as a bypass graft only for target coronary arteries with stenosis of $90 \%$ or greater. A high intraoperative RA graft flow and low PI are not appropriate parameters for the prediction of RA patency.

\section{Limitations}

The present study is a consecutive 1-year follow-up of our first series of patients undergoing endoscopic RA harvesting. We compared patency rates with those of a control group selected retrospectively from our database and literature data. However, to prove the superiority of either technique, a prospective randomized study is needed. The resolution of the computed tomography angiography limits the differentiation between a complete graft occlusion and a functional occlusion with a minimal residual flow. The target vessel stenosis was visually assessed. However, this method may be affected by the individual investigator. Because our study population consisted of only 50 patients, only large effects were identified.

\section{References}

1. Acar C, Jebara VA, Portoghese M, Beyssen B, Pagny JY, Grare P, et al. Revival of the radial artery for coronary artery bypass grafting. Ann Thorac Surg. 1992;54:652-9; discussion 659-60.

2. Fremes SE, Christakis GT, Del Rizzo DF, Musiani A, Mallidi H, Goldman BS. The technique of radial artery bypass grafting and early clinical results. J Card Surg. 1995;10:537-44.

3. Reyes AT, Frame R, Brodman RF. Technique for harvesting the radial artery as a coronary artery bypass graft. Ann Thorac Surg. 1995;59: 118-26.

4. Desai ND, Cohen EA, Naylor CD, Fremes SE. A randomized comparison of radial-artery and saphenous-vein coronary bypass grafts. $N$ Engl J Med. 2004;351:2302-9.

5. Bleiziffer S, Libera P, Lange R. Endoscopic radial artery harvesting through a single incision. Thorac Cardiovasc Surg. 2006;54:208-9.

6. McGowan JH, Cleland JGF. Reliability of reporting left ventricular systolic function by echocardiography: a systematic review of 3 methods. Am Heart J. 2003;146:388-97.

7. Patel AN, Henry AC, Hunnicutt C, Cockerham CA, Willey B, Urschel $\mathrm{J}$, et al. Endoscopic radial artery harvesting is better than the open technique. Ann Thorac Surg. 2004;78:149-53.

8. Khot UN, Friedman DT, Pettersson G, Smedira NG, Li J, Ellis SG. Radial artery bypass grafts have an increased occurrence of angiographically severe stenosis and occlusion compared with left internal mammary arteries and saphenous vein grafts. Circulation. 2004;109: 2086-91.

9. Calafiore AM, Di Mauro M, D’Alessandro S, Teodori G, Vitolla G, Contini M, et al. Revascularization of the lateral wall: long-term angiographic and clinical results of radial artery versus right internal thoracic artery grafting. J Thorac Cardiovasc Surg. 2002;123:225-31.

10. Nezic DG, Knezevic AM, Milojevic PS, Dukanovic BP, Jovic MD, Borzanovic MD, et al. The fate of the radial artery conduit in coronary artery bypass grafting surgery. Eur J Cardiothorac Surg. 2006;30: 341-6. Epub 2006 Jul 7.

11. Buxton BF, Raman JS, Ruengsakulrach P, Gordon I, Rosalion A, Bellomo R, et al. Radial artery patency and clinical outcomes: fiveyear interim results of a randomized trial. J Thorac Cardiovasc Surg. 2003;125:1363-71.

12. Webb CM, Collins P, Chong CF, De Souza AC, Pepper JR, Moat NE. A randomized trial of radial artery and saphenous vein grafts: 5-year patency. Circulation Suppl. 2006;114:II-429.

13. Manabe S, Sunamori M. Radial artery graft for coronary artery bypass surgery: biological characteristics and clinical outcome. J Card Surg. 2006;21:102-15.

14. Zacharias A, Habib RH, Schwann TA, Riordan CJ, Durham SJ, Shah A. Improved survival with radial artery versus vein conduits in coronary bypass surgery with left internal thoracic artery to left anterior descending artery grafting. Circulation. 2004;109:1489-96.

15. Miles RH, Kollpainter RE, Riveron FA, Johnkoski JA. The pneumatic tourniquet technique for endoscopic radial artery harvest. J Card Surg. 2004;19:495-8.

16. Yoshizaki T, Arai H, Igari T, Tabuchi N, Tanaka H, Sunamori M. Endoscopic radial artery harvesting: our initial experience and results of the first 25 patients. Ann Thorac Cardiovasc Surg. 2005;11:391-6.

17. Massetti M, Babatasi G, Bruno P, Le Page O, Neri E, Nataf P, et al. Less invasive radial artery harvest. Heart Surg Forum. 2002;5(Suppl 4):S392-7.

18. Onorati F, De Feo M, Cristodoro L, Esposito A, Perrotti A, Mastroroberto $\mathrm{P}$, et al. Can harvesting techniques modify postoperative results of the radial artery conduit? Ital Heart J. 2005;6:911-6.

19. Cikirikcioglu M, Yasa M, Kerry Z, Posacioglu H, Boga M, Yagdi T, et al. The effects of the Harmonic Scalpel on the vasoreactivity and endothelial integrity of the radial artery: a comparison of two different techniques. J Thorac Cardiovasc Surg. 2001;122:624-6.

20. Shapira OM, Eskenazi BR, Anter E, Joseph L, Christensen TG, Hunter $\mathrm{CT}$, et al. Endoscopic versus conventional radial artery harvest for coronary artery bypass grafting: functional and histologic assessment of the conduit. J Thorac Cardiovasc Surg. 2006;131:388-94.

21. He GW, Yang CQ. Comparative study on calcium channel antagonists in the human radial artery: clinical implications. J Thorac Cardiovasc Surg. 2000;119:94-100. 
22. Chamiot-Clerc P, Copie X, Renaud JF, Safar M, Girerd X. Comparative reactivity and mechanical properties of human isolated internal mammary and radial arteries. Cardiovasc Res. 1998;37: $811-9$.

23. Tatoulis J, Buxton BF, Fuller JA. Patencies of 2127 arterial to coronary conduits over 15 years. Ann Thorac Surg. 2004;77:93101.
24. Desai ND, Naylor CD, Kiss A, Cohen EA, Feder-Elituv R, Miwa S, et al. Impact of patient and target-vessel characteristics on arterial and venous bypass graft patency: insight from a randomized trial. Circulation. 2007;115:684-91.

25. Royse AG, Royse CF, Tatoulis J, Grigg LE, Shah P, Hunt D, et al. Postoperative radial artery angiography for coronary artery bypass surgery. Eur J Cardiothorac Surg. 2000;17:294-304. 